\title{
THE MENTAL DEVELOPMENT OF CHILDREN FROM MULTIPLE PREGNANCY
}

\author{
J. SLENZAK, M. BRINCKEN, D. CHRZANOWSKA, \\ E. KULINSKA, K. ZORSKA
}

Department of Child Development, National Research Institute for Mother and Child, Warsaw, Poland

A total of 59 children from multiple pregnancy, aged from 18 months to 13 years, bave all shown a mental development within or above normal limits.

In 18 children there are reasons to suspect the presence of a CNS lesion, although the general mental level is good.

The numerical concordance of intelligence quotients is not typical for $M Z$ and $D Z$ twins. In four cases there were marked qualitative differences despite IQ concordance.

The behavior of twins in their bome, preschool, and school environment, is determined by the separate nature of the relationship in which the twins live since birth.

A child develops in multiple pregnancy under conditions differing from those of a child in single pregnancy. This involves both the course of pregnancy, of labor, and then the environment in which the child grows.

The undertaken evaluation of the development of children from multiple pregnancy is an attempt at giving an answer to the question whether the differences in development exert an influence, and what an influence, on the mental development of children. In the analysis of our material, we have taken into account the level of mental development (in younger children, the level of psychomotor development), the forms of behavior and personality traits.

\section{MATERTAL AND METHODS}

The material consisted of 81 children, 78 from a twin pregnancy and 3 from a triplet pregnancy. A total of 63 children were under the care of the Pediatric Outpatient Department of the City of Warsaw, 18 were treated at the Clinical Department of Metabolic Studies and at the Clinical Department of Child Neurology of the National Research Institute for Mother and Child in Warsaw.

The material presented included $15 \mathrm{MZ}$ twin pairs, $24 \mathrm{DZ}$ twin pairs, and one group of triplets. The children's age varied from 2 months up to 13 years.

In order to evaluate mental development, the authors applied, according to the children's age group, Brunet-Lézine Scale of Psychomotor Development, Terman-Merill Scale, Wechsler Intelligence Scale for Children. By means of interviews and psychological observation it was possible to assess the children's behavior and their personality traits. 


\section{RESULTS AND DISCUSSION}

The infants whose age did not exceed one year formed a group of 22. As the observations on them are under way, their preliminary summing up is the subject of a separate report, but observations which are connected with the way how the relation between parents and twins evolve at this stage of life have been studied.

The assessment of the level of psychomotor and mental development of the remaining 28 pairs and of the group of triplets showed that 44 children had a DQ or IQ of 90-110, 10 children of over 110, and 5 children of 80-90.

As it results from these data, no mental deficiency was found among the children studied. In 18 of them, there are reasons to suspect microlesions of the central nervous system, which are betrayed by either a lower functional efficiency of the visual, acoustic, and kinesthetic analyser on the background of a good general intellectual level or by psychomotor hyperexcitability. The above disturbances have become the subject of further intensified psychological and medical studies which are still being continued, but are not mentioned in the present paper. They involve both MZ and DZ twins.

The question was taken into account whether intelligence or development quotients were the same in cotwins. It was found that only in 4 pairs ( $2 \mathrm{MZ}$ and $2 \mathrm{DZ})$ the quotients were the same, whereas 13 pairs $(2 \mathrm{MZ})$ differred by 5 points, 5 pairs $(3 \mathrm{MZ})$ by $5-10$ points, and 7 pairs $(1 \mathrm{MZ})$ by over 10 points.

The too small number of children observed did not permit to carry out a comparative analysis if the numerical differences between intelligence quotients in $M Z$ and $D Z$ twins, but the authors found that, even in the 4 pairs who obtained the same numerical results, considerable qualitative differences appeared from the point of view of drive, motivation activity, and they involved even the youngest children.

The observation of the behavior of twins as early as in infancy permits to assume that the fact of the possession of a peer, sometimes of the same sex, is of great importance for the emergence of some forms of behavior.

In a test on the reaction of the infant to its own reflection in a mirror, the infant behaved in the same manner as when it was set in contact with its sibling. It was noted that 2 to 3 year-old twins most often took up any action in common. This may result from the fact that the parents and educators treat the two infants as one whole, and the response of the twins, particularly of the youngest ones, is also only one.

During the examinations it was noted that the execution of a task by one girl at the age of 3 years depended on the approval of the same by her twin sister. In some cases, with 2-3 year-old children, it was necessary to leave the other twin in the room of examinations, as the separation of the children made them anxious and had a negative effect on the results. A phenomenon of this kind was noted by Newman et al. (1937) when he found that twins examined in separate rooms showed lower test results. It seemed as if one child needed the presence of the other in order to obtain the maximal effect.

Twins are sometimes so closely attached to each other that they try to isolate themselves from the environment. In the case of two pairs of MZ twins (aged 2 and 8 years), the authors noted that the children developed their own specific language.

In such situations the inclusion of the twins in a group of peers encountered great diff- 
culties. In some cases, educators agreed that the pairs of twins tend to keep together and to act besides the group of children, but not in it.

As the social contacts with other children are established, this link becomes somewhat looser, but it seems to be of further significance for the shaping of some attitudes and kinds of behavior. The pair of twins is a relationship of two human beings of the same age continually living together (if they are brought up in the same home). Exerting an influence on each other, they shape one another, and in the process of the singling out of their own personality, they are a point of reference for themselves. It is also understandable that, in the relationship of two persons, the dominant one induces in the other person an attitude of subordination; taking over the initiative, it becomes the cause of the limitation of the independence of the other person; this elicits a favorable situation for the shaping of diverse forms of behavior in the two children. 